\title{
Um olhar para a clínica de crianças e adolescentes - relato de experiência
}

\author{
A look over the clinic of infants and \\ teenagers - a report of an experience
}

\author{
Andrea Perosa Saigh Jurdi ${ }^{1}$, Maria Inês Britto Brunello², Andréa do \\ Amparo Carotta ${ }^{3}$, Wilson R. Tamborini ${ }^{4}$
}

\begin{abstract}
JURDI, A. P. S.; BRUNELLO, M. I. B.; CAROTTA, A. A.; TAMBORINI, W. R. Um olhar para a clínica de crianças e adolescentes - relato de experiência. Rev. Ter. Ocup. Univ. São Paulo, v. 17, n. 1, p. 26-32, jan./abr. 2006.

RESUMO: Este artigo se propõe a relatar, através de um estudo de caso, a clínica desenvolvida pelo Espaço Lúdico Terapêutico. Partimos do princípio que para produzir saúde, esta clínica deve oferecer mais que o atendimento terapêutico. Ela deve ultrapassar seus limites e agregar ao seu conhecimento outros saberes, construindo um novo modo de olhar e pensar sobre a infância e a adolescência com deficiência. Ao relatar este caso ressaltamos que a clínica de crianças e adolescentes tem peculiaridades e nos leva a um trabalho diferenciado, que percorre o cotidiano dessa população, as parcerias e intervenções em outras instituições, realizando um trabalho interdisciplinar.
\end{abstract}

DESCRITORES: Crianças portadoras de deficiência/reabilitação. Assistência ambulatorial/tendências. Instituições de assistência ambulatorial. Equipe de assistência ao paciente. Relações comunidade-instituição. Terapia ocupacional. Formulação de políticas.

\section{INTRODUÇÃO}

$\mathrm{O}$ s 10 anos de existência do Espaço Lúdico Terapêutico (ELT) estão relacionados às histórias de vida de crianças, adolescentes e famílias que chegaram e continuam chegando até nós. São histórias de repetidos fracassos, de negativas de vagas em assistência e educação, e de dificuldades de constituir uma vida digna, direito de todo cidadão. Trazem queixas relativas às dificuldades que a deficiência impõe: dependência,

\footnotetext{
${ }^{1}$ Terapeuta Ocupacional do Curso de Terapia Ocupacional da USP, membro do laboratório de Estudos sobre Cotidiano e Deficiência, Mestre e Doutoranda em Psicologia Escolar e Desenvolvimento Humano pelo Instituto de Psicologia da USP. E-mail: ajurdi@usp.br

${ }^{2}$ Docente do Curso de Terapia Ocupacional da USP, Coordenadora do Laboratório de Estudos sobre Cotidiano e Deficiência, Doutora em Psicologia Escolar e Desenvolvimento Humano pelo Instituo de Psicologia da USP. E-mail: maribrunello@hotmail.com

${ }^{3}$ Terapeuta Ocupacional do Curso de Terapia Ocupacional da USP, membro do Laboratório de Estudos sobre Cotidiano e Deficiência, mestranda em Psicologia Clínica da Puc-SP.

${ }^{4}$ Psicanalista, membro do Laboratório Sujeito e Corpo (SuCor), do Departamento de Psicologia Clínica do IP-USP.

Endereço para correspondência: Rua Cipotânea, 51. Cidade Universitária. São Paulo, SP. CEP: 05360-160.
} 
isolamento, dificuldade em aprender, atrasos no desenvolvimento e na sua maneira de estar no mundo. Dessas dificuldades resulta a privação social de crianças e famílias e a cronificação de relações que se estabelecem sobre o estigma da exclusão.

Enquanto profissionais do ELT tínhamos dois caminhos: absorver, concordar com as queixas e continuar reproduzindo, através dos atendimentos clínicos, os modelos de exclusão que essa população tem sofrido ou pensar em uma clínica que trouxesse alternativas e rompesse com as ações excludentes.

Optamos por pensar a clínica tendo como objetivo um olhar cuidadoso para as atividades que compõem o cotidiano dessas pessoas, em busca de uma melhor qualidade de vida, estruturando a instituição de forma que esta pudesse oferecer brechas de todos os tipos, possibilitando às crianças, adolescentes e famílias uma circulação social ampliada.

A proposta do ELT em oferecer possibilidades de um viver mais criativo, estabelecendo pontes com o outro e com o próprio desejo, foi se configurando como um espaço de oportunidades para novos agenciamentos e encontros, que viabilizaram novas formas de circulação social e favoreceram a entrada nos processos vitais da infância e da adolescência. Assim, o ELT direcionou sua prática para a construção de espaços de socialização, em oposição aos espaços terapêuticos tradicionais.

Este trajeto somente aconteceu quando, diante das necessidades trazidas por tantas crianças, adolescentes e famílias, juntos rompemos com a imobilidade existente e construímos dispositivos de sustentação social capazes de produzir mudanças, na qualidade de vida desses sujeitos.

Para efetivar o compromisso com essa clínica sabemos que devemos nos propor a ir além das estratégias terapêuticas tradicionais. Crianças e adolescentes necessitam ter assegurado para si laços sociais que permitam seu crescimento e desenvolvimento. Por este motivo acreditamos que a montagem institucional exige ações, não somente de uma atenção especial ao sujeito, mas também, às famílias, às escolas e à comunidade, que compõem a construção e o fortalecimento das redes de sustentação social.

Este artigo está dividido em quatro partes. A primeira se refere ao relato de experiência do ponto de vista da equipe do ELT em relação à criança atendida. A segunda parte constitui-se do relato do psicanalista e seu olhar sobre essa criança, que através de sua práxis, pôde auxiliar na composição da trama do tecido desta rede. A terceira e a quarta parte se referem à abordagem familiar e escolar, respectivamente e foram feitas pela equipe do ELT. Esta justaposição de relatos nos faz caminhar por diferentes espaços e nos oferece uma forma de pensar a clínica da infância e adolescência.

O relato, na voz do psicanalista, mostra a mesma criança pensada de um outro lugar. Isso enriquece o trabalho de todos, pois acreditamos que essas parcerias não se resumem a agregar somente as diversas formas de pensamentos e teorias, mas de construir uma práxis interdisciplinar, capaz de mobilizar efeitos significativos nas áreas da saúde, educação, família e comunidade, fundamentais na construção desse projeto.

É importante assinalar que o relato foi construído após o consentimento informado da família.

\section{EU, M.... o relato de experiência a partir do olhar da Terapia Ocupacional}

A entrada da criança que denominamos de M. no ELT se deu em maio de 2002, quando tinha sete anos de idade. Sem um diagnóstico definido, apresentava dificuldades de relacionamento, de aprendizagem e um distanciamento da própria família.

No primeiro contato realizado com a família, a mãe falava muito sobre as dificuldades da filha, desde o seu nascimento, ressaltando problemas no seu desenvolvimento intelectual e psicomotor, que persistiam até aquele momento. M. era caçula, de uma família nordestina, que estava migrando para São Paulo. Nasceu de parto normal, sem nenhum tipo de problema, numa família de seis irmãos - dois homens e quatro mulheres.

Percebeu que a sua filha tinha dificuldades para se comunicar quando esta com três anos de idade não falava direito, não expressava o que queria e não se relacionava naturalmente com as crianças da sua idade. Como era sua filha caçula, pôde compará-la com os seus outros filhos e constatar que o seu desenvolvimento não estava compatível com a sua idade. Naquela época não pôde tomar nenhuma providência, porque estavam passando por período de extrema necessidade.

Ao longo de seu desenvolvimento a criança parece sofrer interrupções no processo de amadurecimento de acordo com as mudanças que ocorreram na família: mudanças constantes de casas, cidades e, por último, a vinda para São Paulo. Como exemplo, a mãe relata que, em uma determinada época, a filha estava aprendendo a andar e parou quando se mudaram de uma cidade pequena para uma outra cidade maior. Quando se mudaram para São Paulo, a filha mostrou-se cada vez mais retraída. Para o pai e para a mãe sua filha não era normal, não era como uma menina de sete anos e acreditavam que tivesse um problema neurológico. Sua mãe afirmava que até hoje M. tinha 
dificuldades para comer sozinha, tomar banho, que confundia as letras do alfabeto, não sabia ler, tampouco escrever. Não tinha amiguinhas, não sabia brincar e se comunicava com dificuldade quando queria alguma coisa.

Quando conhecemos M. esta se apresentou muito tímida, amedrontada, com um certo distanciamento da realidade. Referia-se a si mesma na terceira pessoa, repetia falas descontextualizadas que pareciam ser de outras pessoas.

Nos mobilizou pela sua fragilidade emocional e psíquica, mas também por um certo pedido de ajuda de sua parte: em determinado momento da brincadeira, pegou um gibi de cabeça para baixo e começou a contar uma história que parecia não ter fim. De repente começou a falar: "Você é uma menina burra. Será que nunca vai aprender? Eu ensino você, mas você nunca aprende. Sua burra, burra, burra”. Depois voltou para sua história monotonamente.

Nossa leitura foi que neste momento não apenas a família pedia ajuda, mas a própria criança apontava que precisava ser cuidada. Mostrou-nos que sua fragilidade psíquica vinha de um ambiente cheio de percalços, que não conseguia atender suas necessidades básicas.

Assim, M. começou a freqüentar um grupo de crianças de sua idade no ELT e por meio da brincadeira foi contando e recontando sua história e seu percurso de vida. Montava sua casa, cozinhava e fazia com que o grupo vivenciasse sua experiência. No papel de mãe obrigava-nos a comer muita comida, organizava as brincadeiras, ocupando a liderança do grupo. Em determinado momento do processo terapêutico deixou de ser a mãe e passou a se vestir de boneca e, como a boneca Emília, pedia para que a denominássemos por este nome. Ao oferecermos esse espaço de criação e elaboração das vivências passadas e presentes, M. pôde se apropriar de sua história e contá-la. Mas precisava ainda de um apoio, um ego auxiliar: a boneca Emília. E a explicação vem da própria criança: “a Emília é uma boneca e boneca pode tudo e nunca é castigada. Pode falar o que quiser e fazer o que quiser". M. se apodera da independência e da autonomia de uma boneca cheia de vida e muito traquina. Para ela isto teve um significado muito importante.

Ao longo de seu processo terapêutico percebemos mudanças rápidas que afetaram a dinâmica familiar. Sua fala se transforma, contextualizada na brincadeira que elabora. Seu desenvolvimento avança. A mãe passou a referir que $M$. não é mais a mesma, não para quieta, pede tudo o que vê pela frente com uma voracidade que assusta os pais.

Nesta fase, uma intensa agitação motora tomou conta de M. e tudo o que realizava era excessivo: potes e potes de tinta são descarregados em suas pinturas; saltos, piruetas, gritos acontecem em excessiva velocidade. M. se transforma de uma criança sem espaço em uma criança espaçosa.

Neste momento, a mudança da expressão verbal e os importantes conteúdos trazidos por M., nos levaram a propor que ao nosso trabalho pudesse somar-se o atendimento psicanalítico. Encaminhada ao Laboratório Sujeito Corpo, do Instituto de Psicologia da USP, nos mostra a menina cor-de-rosa, vista sob outro ângulo, nos ajudou a compor o trajeto dessa criança.

\section{A menina cor-de-rosa - o olhar da psicanálise}

A história e a graça com que essa criança - "a menina cor-de-rosa" - se apresentou no primeiro dia da entrevista com a família e em muitos outros do seu tratamento, despertaram o meu interesse em atendê-la. Quando conheci a menina, 8 anos, mestiça, pele morena, com cabelos castanho escuro, em cachos e presos com enfeites cor-derosa, tênis, calça e blusa, também, cor-de-rosa - dos pés a cabeça rosa - e ouvi as queixas de sua mãe, pude reconhecer que havia nelas um pedido de ajuda e me dispus a atendêlas pensando que talvez eu pudesse aplacar um pouco o sofrimento que viviam.

Temos como procedimento no SuCor - Laboratório Sujeito e Corpo, que a criança não esteja presente na primeira entrevista com os pais. Mas, no caso de M. os pais a trouxeram. Nesta entrevista, após uma discussão entre a mãe e o pai, sobre a cor de M., pois a mãe considerava que a filha fosse negra e o pai dizia serem a filha e ele pardos, M. disse: "Eu... sou... cor-de-rosa!".

Esse momento evidenciou o seu desejo enquanto Sujeito, considerei que ser cor-de-rosa foi a maneira que M. encontrou para aplacar a sua angustia diante de uma situação que pouco ou quase nada poderia fazer. De imediato fui tomado por aquilo que Lacan descreve em seu seminário, livro VIII, sobre a transferência:

"Esta mão que se estende para o fruto, para a rosa, para a acha que se inflama de repente, seu gesto de pegar, de atrair, de atiçar é estreitamente solidário à maturação do fruto, à beleza da flor, ao flamejar da acha. Mas quando, nesse movimento de pegar, de atrair, de atiçar, a mão foi longe o bastante em direção ao objeto, se do fruto, da flor, da acha, sai uma mão que se estende ao encontro da mão que é a de vocês, e neste momento é a sua mão que se detém fixa na plenitude fechada do fruto, aberta da flor, na explosão de uma mão em chamas - então, o que aí se produz é o amor" (LACAN, 1992, p. 99).

Desde o primeiro momento que a vi, o meu desejo de 
analista foi provocado: queria saber mais sobre a sua história, seu sintoma. E por mais que a mãe apresentasse motivos e fatos para demonstrar o quanto a sua filha era inepta e o pai concordasse, sem nada a acrescentar, eu ouvia atentamente e me perguntava onde será que estava o enigma daquela história, que a mãe e o pai haviam construído sobre a sua filha.

Hoje posso dizer que o pedido de ajuda veio através dessa maneira exagerada da mãe falar sobre o comportamento de sua filha. Não foram poucos os seus esforços para que M. pudesse prosseguir a sua análise, e graças a uma forte parceria da mãe comigo ela pode realizar o seu tratamento com êxito.

Bastava uma gripe ou dor de garganta para que $\mathrm{M}$. dissesse: "Você está vendo como eu sou doente! Olha só como eu estou gripada...!" Somente após o desenvolvimento do tratamento, pude constatar, aquilo que no início eu pressentia: ver a filha como doente e ser vista como tal foi o arranjo que a família encontrou para dar um lugar a M. e tratá-la. Estranhos caminhos aqueles que o inconsciente traça e daí termos de ouvir com muito cuidado a demanda que um pedido esconde.

Nas primeiras sessões, ao chegar na sala, M. ficava calada, olhava-me atentamente, falava ou tentava escrever coisas desconexas, muitas vezes ia até a lousa, rabiscava tudo, depois, corria para todo canto da sala, não atendia aos meus pedidos e algumas vezes tinha fala truncada. Agia como se não compreendesse o que lhe era dito, ou falava coisas sem sentido. Mas procurava, durante as sessões, fazer um desenho, ou tentava escrever o seu nome em letra de forma e no final apresentava para minha apreciação, esperando que eu a aplaudisse, pois sabia que era muito importante aos pais que ela fosse bem na escola. Após alguns encontros comecei a não demonstrar muito interesse por essa sua maneira de se expressar, insistindo que ali não era escola realçando que naquela sala poderíamos fazer outras coisas.

Após longo período sem que houvesse qualquer tipo de resposta, M. resolveu se interessar pelos outros objetos, mas não permitia nenhuma intervenção. Era ela quem dizia o que deveria ser feito e de que maneira. Nessa época $M$. não falava nenhum nome próprio de homem, inclusive o meu. E quando se dirigia ao nome do pai utilizava algum tipo de substantivo masculino ou feminino para identificálo. Seus substantivos favoritos eram as frutas: "aquele maçã" ou "aquele abacaxi" e por aí ela ia tecendo os seu comentários.

Mesmo que M. não dissesse nenhum nome de homem e tampouco aparentasse aceitar qualquer tipo de regra diferente da sua, já estava oscilando para uma nova posição.
E, portanto, até onde era possível eu permitia que ela fizesse à sua maneira, pois era também a forma dela dizer onde queria chegar.

Minha intenção era provocar uma situação em que o reconhecimento da representação simbólica de uma lei pudesse lhe conferir uma nova posição, não somente no espaço analítico, mas em sua vida. Dessa maneira as suas atitudes, o seu discurso, não eram mais os mesmos de antigamente, como se tivesse ocorrido uma modificação em seu sintoma. A mãe compreendia as mudanças como agudização dos sintomas, passando a me procurar para reclamar que a sua filha estava piorando.

A minha preocupação não era a agudização do sintoma de M., e sim o que a sua mãe poderia resolver fazer com isso. Uma vez que eu sabia qual a representação que as atitudes de M. tinham no núcleo familiar, cuidava para que o tratamento não fosse interrompido.

Esse foi um dos momentos de muito risco, exigiu ampla disponibilidade para escutar a mãe de M. e enquanto acolhia as suas queixas, privilegiava os momentos em que ela podia reconhecer a filha não mais como a doente da família, mas, sim, como um sujeito singular e repleta de possibilidades.

Após insistentes investidas de M. ao meu lugar de analista, pedindo provas dessa minha posição, de tal maneira que lhe fosse possível à construção de uma nova significação de si e do seu desejo, pautada numa dialética da simbolização da lei, que a convocou inevitavelmente ao jogo das identificações, ela, mais uma vez e rapidamente, transformou a sua maneira de ser e estar em análise.

Para ilustrar este fato, trago uma, entre varias sessões, que marca esta passagem tão singela e importante na construção de um Sujeito que considera a unidade imaginária de um corpo, desenvolvida através de uma imagem especular e que Lacan (1992), descreve, na sua proposta do estádio do espelho como formador da função do eu: M. retira da mochila um vidro de perfume, brilho para os lábios e batom, fez questão de se "maquiar" olhando para o espelho e mantendo a minha atenção. E, ao terminar, olhando-me disse: "Era tudo que hoje eu queria". Aproveitei essa frase de M., decidi prosseguir e lhe perguntei: "E..., mais o quê você deseja? Então, ela se dirigiu até a lousa, escreveu o seu nome ao lado do meu, desenhou mais algumas figuras e fez uma nuvem em volta. Ficou de costas, abriu os braços, encostou-se na lousa, olhou para o espelho, onde essa imagem se refletia, junto a minha, e com ar de satisfação, disse:" "Olhe... que bonito!".

Mesmo que M. tivesse dito: "Era tudo que hoje eu queria". Não disse nada, do que queria. Somente o júbilo de ver a sua imagem refletida no espelho junto com a minha, lhe permitiu manifestar o que queria: ver e ser vista por 
inteiro, esse era o efeito imaginário que o seu desejo buscava na completude de um corpo não despedaçado, em que a falta não existia diante do Outro.

Esta construção que agora M. podia realizar sobre si mesma e o outro, sob a égide da linguagem, traduzia a sua condição para o jogo completo dos objetos, permitindo o seu acesso ao simbólico, afastando-a de seu assujeitamento imaginário do lugar de doente, começava um novo momento em que poderia ser sujeito desejante.

Esta nova postura de M. ficava evidenciada, não somente por suas atitudes, mas, sobretudo na sua maneira de se expressar, no seu discurso e nas revelações que fazia, através das associações que realizava, sinalizando o final do tratamento, conforme relato a seguir:

Um dia M. chega com o seu álbum da Barbie e pede que eu escolha um acessório para a boneca. Depois pergunta para mim: "Qual dessas duas Barbies você acha mais bonita? A loira ou a morena?" Eu lhe respondo: "M. cada uma tem a sua beleza". E ela imediatamente diz: "Por que você não pode escolher uma das duas?".

Nessa sua questão já estava inscrito o que de início não era possível ser questionado: qual era o seu lugar? E, quem sabe agora, ela pudesse assumir uma nova posição, ter um olhar diferente sobre si mesma e o outro e então deixar de ser cor-de-rosa. E se assim fosse havia chegado o momento de encerrar o tratamento.

Quando M. encerrou o seu tratamento pediu se poderia levar uma das bonecas que compunha a sua caixa de brinquedos. Escolheu àquela que, no início de seu tratamento, nomeou de Rafaela - vestida dos pés à cabeça de cor-de-rosa.

\section{O acolhimento da família no ELT}

O atendimento da família no ELT consistiu inicialmente, na abordagem individual de orientação e posteriormente, a mãe passou a participar de um grupo para familiares. Em 2000, quando M. completou cinco anos, sua mãe teve que sair da Bahia para trabalhar em São Paulo. A família veio em etapas, como freqüentemente acontece nessas situações, e embora os outros filhos permanecessem na Bahia, a mãe preferiu trazer a filha consigo, pois era muito pequena. Durante quatro meses $\mathrm{M}$. ficou na casa da tia, enquanto a mãe trabalhava fora como babá de trigêmeos. Após este período, a penúltima filha, na época com treze anos veio ajudar a cuidar de M. Seis meses depois, continuando o processo migratório, vieram para São Paulo o pai e a irmã mais velha e somente no início de 2003 toda família conseguiu se reunir novamente.

No início do atendimento o pai e a irmã mais velha de
M. revezam-se para trazê-la ao serviço. O pai, pouco acessível a trocas, a irmã mais acessível e tranqüila e com a qual M. parecia estar muito feliz. Naquele momento a mãe era a provedora da casa, trabalhava como babá e vinha para casa apenas em suas folgas semanais.

M. se liga muito à irmã mais velha que a incentiva e estimula. Segue as orientações dadas e é quem efetiva os encaminhamentos sugeridos pela equipe. Esta irmã tem um papel fundamental na vida de M., pois é a única que se recusa a reconhecer $M$. como doente, sustentando que ela é uma criança normal. Acolhe a fase de intensa vivência corporal, oferece e respeita o espaço para M. ser Emília, estimula a irmã em seu aprendizado; lhe ensina as horas e lhe compra um relógio e o primeiro sutiã. Faz o papel da mãe que, por necessidade, encontrase ausente. Esse foi o período de grandes transformações no desenvolvimento de $\mathrm{M}$.

Devido a um problema de saúde, a mãe para de trabalhar e passa a acompanhar a filha aos tratamentos. Assim, a mãe começou a freqüentar o grupo de família no ELT e trazer os problemas referentes à dinâmica familiar. Acirra-se o conflito entre o pai, alcoolista e o filho, drogadito. As brigas são freqüentes com cenas de violência e idas à polícia. M. se fragiliza com esses conflitos.

Foi fundamental, neste período, o trabalho com a mãe para que esta percebesse que o foco da doença não estava em M., mas sim em outros componentes da família e pudesse valorizar e priorizar os atendimentos de sua filha.

Ao mesmo tempo, o percurso de M. lhe mostra que está crescendo e que não precisava da boneca Emília para construir seu lugar no mundo. Aos 10 anos, comemorou seu aniversário com amigas que antes não tinha, passou a usar roupas da Barbie e tornou-se fã da boneca. Usava os acessórios, roupas e bolsas, comportava-se como uma menina de 10 anos, criticando a falta de compostura dos meninos do grupo. É uma menina que passa a fazer amigos na escola, vai a passeios e brinca na rua.

Junto com o interesse em crescer e descobrir o mundo, M. começou a se conhecer melhor, trazendo necessidades e desejos de uma criança de sua idade. Durante o convívio M. foi demonstrando habilidades e desejos de aprender atividades de dança e esporte e sentia-se segura para freqüientar outros espaços. O serviço passou a acompanhála neste sentido.

Concomitantemente a família foi orientada a dar continuidade à participação de $\mathrm{M}$. nesses novos espaços.

Percebemos o aumento da autonomia, tanto de $\mathrm{M}$. como de sua família para lidar com as dificuldades. Chegou a hora da alta. O grupo terapêutico foi importante e fundamental em uma determinada fase da vida dessa criança 
que pôde construir seu próprio percurso a partir de um espaço de continência.

A mãe começou a sair mais com a filha, levá-la ao equipamento social próximo à sua casa, buscando recursos para si mesma e para a filha.

Observamos que o acolhimento familiar propicia a mudança dos sentimentos de impotência e fracasso da família frente a um filho com dificuldades. O oferecimento de novas possibilidades de existência abre novas perspectivas de vida aos sujeitos. A possibilidade de ir ao cinema, freqüentar uma sala de aula, passear no parque modificam relações e estabelecem perspectivas de mudanças.

Assim como pensamos a inserção social das crianças e adolescentes é prioritário que pensemos também sobre a mesma inserção da família. Lerner (1997) afirma que tão importante quanto pensar a integração da criança na família é pensar a integração da família na comunidade.

\section{A Escola - mais um ambiente de confiabilidade}

Ir à escola nunca foi muito fácil para M., após freqüentar a pré-escola foi matriculada em uma escola estadual para cursar a primeira série. Quando iniciou o atendimento, M. parecia ser vítima de violência na escola e isso não era percebido por seu professor. Por sua vez, a mãe não tomava a iniciativa de discutir ou mudar a filha de escola. Talvez por pensar que o problema estivesse com a filha e não com a escola.

Em agosto de 2002, M. passou a freqüentar uma escola municipal, próxima à sua casa e foi iniciada a parceria, fundamental para o processo, com a Coordenadoria de Educação do Butantã. Através da equipe que trabalha com inclusão de crianças com deficiência, foi possível abrirmos um diálogo com a escola e facilitar o complexo processo de inserção escolar de M. Para que o processo se efetivasse foi necessário acionar a rede composta pela família, escola e saúde.

Quando M. foi para a segunda série, iniciamos um trabalho de orientação com a professora. Uma vez por mês, íamos à escola e conversávamos com a mesma, que colocava suas dúvidas, incertezas e desejos em relação ao aprendizado de sua aluna. Trabalhamos muito com o desejo e com a percepção da professora sobre a aluna e esse foi o grande trunfo dessa parceria.

Da mesma forma que asseguramos um espaço de criação para M., oferecemos à professora espaço para que pudesse criar, imaginar, se apropriar de seus conhecimentos, inventá-los e reinventá-los. Oferecemos uma relação de confiabilidade, assim, professora e aluna puderam criar, aprender e transgredir no ambiente escolar, fato que foi fundamental para o aprendizado de M. e, certamente para o aprendizado da professora.

Ao final do ano letivo, M. estava lendo e escrevendo. Muito feliz começou a ter outro lugar na escola e na família.

Tentamos contato com a nova professora que avaliou que M. estava no nível da classe e que não necessitava de auxílio. Na quarta série M. também se manteve no nível da sala e a professora se admirou quando perguntamos por M., pois esta não apresentava qualquer diferença de seus alunos. Estava incluída, tinha amigos, ia a passeios e mantinha seu aprendizado.

Durante a parceria com a educação foi necessário a participação da família, sustentando a importância da escola, do aprendizado e a crença de que $\mathrm{M}$. pudesse aprender. $\mathrm{O}$ desejo de todos nós se transformou no desejo de aprender de M.

Para Rosa (1996) a escola, como o primeiro ambiente fora do âmbito escolar, recepciona e coloca o futuro adulto na esfera das relações sociais. Por isso, a importância das primeiras experiências vividas neste contexto será decisiva para a construção do modo do indivíduo se colocar no mundo, nas relações com o outro, e frente ao conhecimento e ao ato criativo.

\section{CONSIDERAÇÕESFINAIS}

Uma história de sucesso não quer necessariamente dizer que todos os problemas foram solucionados. Ao contrário, nos remete aos obstáculos encontrados pelo caminho, nos recursos utilizados para solucioná-los, para que, no final, possamos avaliá-lo como um relativo sucesso.

Esta história só foi possível por integrarmos vários atores e seus saberes aos nossos saberes. Cada parceiro pôde oferecer seu olhar, seu conhecimento, seu desejo para que todos pudessem atingir um objetivo final.

A construção de uma clínica voltada para a assistência da infância e adolescência não se faz solitariamente. Nosso trabalho tem sido sempre uma busca por parceiros que consigam conjuntamente urdir a trama de relações sociais, fundamentais para o crescimento de crianças e adolescentes com prognósticos de vida tão limitados.

Caniza de Páez (2001) refere que as instituições de assistência à pessoa com deficiência sempre trabalharam em vias paralelas, sem ponto de confluência. A autora sugere que é fundamental que se transforme os caminhos de vias paralelas em vasos comunicantes, no qual se facilite que a incidência recíproca entre todos os componentes permita contribuir para que se atinja a inserção social e educacional desta população. 
Nesta abordagem propõe que esse sistema se efetive através de um trabalho entre instituições e/ou entre diversos setores da sociedade. Um sistema no qual a interdisciplina seja o modo de trabalhar.

A inserção social de nossas crianças e adolescentes depende das instituições, das famílias, da comunidade e, principalmente que se faça a pergunta: o que você quer? Sem a resposta da pessoa envolvida pouco poderemos realizar. Através da formulação de um desejo ou necessidade, poderemos criar condições para que essa população saia do lugar de mero espectador dos acontecimentos.

Consideramos que o êxito desse nosso trabalho em parceria, sobretudo, foi possível por estarmos em sintonia com os nossos propósitos, fundamentados em princípios que nos permitiram uma interconexão de idéias e atitudes favoráveis ao bom desempenho do tratamento. E que as nuances do nosso ofício, tornaram-se o escopo por onde dirigimos as nossas ações e, ao fazer, cada um de nós, se fez.

JURDI, A. P. S.; BRUNELlO, M. I. B.; CAROTTA, A. A.; TAMBORINI, W. R. A look over the clinic of infants and teenagers - a report of an experience. Rev. Ter. Ocup. Univ. São Paulo, v. 17, n. 1, p. 26-32, jan./ abr. 2006.

\begin{abstract}
The purpose of this article is to demonstrate, through a study case, the clinic developed by ELT. In order to produce health, we believe that this clinic must offer more than just a simple therapeutical treatment. It should go over its limits and add to its knowledge other knowledgement, building up a new form of looking at and thinking about the handicapped infants and teenagers. As we report about this case, we point out that the clinic of infants and teenagers has its own peculiarities and lead us to a differentiated kind of work, which goes through the daily life of this community, the partnerships and interactions with other institutions, performing a interdisciplinary work.
\end{abstract}

KEY WORDS: Disabled children/rehabilitation. Ambulatory care/trends. Ambulatory care facilities. Patient care team. Community-institutional relations. Occupational therapy. Policy making.

\title{
REFERÊNCIAS
}

CANIZA DE PAEZ, S. As pessoas com necessidades especiais, a comunidade e as instituições. Estilos Clin., São Paulo, v. 6, n. 10, p. 129-140, 2001.

LACAN, J. O Seminário VIII: a transferência. Trad. D. D. Estrada. Rio de Janeiro: Jorge Zahar Editor, 1992.
LERNER, R. Escolarização de crianças portadoras de distúrbios globais de desenvolvimento. Estilos Clin, São Paulo, n. 2, p. 63 $71,1997$.

ROSA, S. S. A dissociação do self e suas implicações na educação. Rev. Percurso, n. 17, p. 75-83, 1996. 